\title{
Mycoplasma pneumoniae: Atypical Pathogen in Community Acquired Pneumonia
}

\author{
Abdul-Rahman Mamdouh Mohammad', Rehab Mahmoud Abd El-Baky ${ }^{2,3}$ \\ and Eman Farouk Ahmed ${ }^{3 *}$ \\ ${ }^{1}$ Faculty of Pharmacy, Deraya University, Minia 11566, Egypt. \\ ${ }^{2}$ Department of Microbiology and Immunology, Faculty of Pharmacy, Minia University, Minia 61519, Egypt. \\ ${ }^{3}$ Department of Microbiology and Immunology, Faculty of Pharmacy, Deraya University, Minia 11566, Egypt.
}

\begin{abstract}
Mycoplasma pneumoniae is a one of most common reasons of respiratory tract infections in both adolescents and children with severity ranged from moderate to high. Many facts in the previous years regarding infections were induced via this organism having extra pathogenic mechanisms. Clinically, resistance to macrolide has produced internationally and represents a treatment trouble. Antimicrobial sensitivity checking out techniques have been applied, and novel antibiotics which are effective towards M. pneumoniae are present processing development. That evaluate concentrates on the several trends occurring in the previous quite a few years which beautify the grasp of that microorganism, which is one of the smallest pathogenic bacteria; however, is of extreme medical significance.
\end{abstract}

Keywords: Mycoplasma pneumoniae, community acquired pneumonia, macrolide resistance, treatment

*Correspondence: eman.farouk@deraya.edu.eg

(Received: September 23, 2020; accepted: October 21, 2020)

Citation: Mohammad A-RM, El-Baky RMA, Ahmed EF. Mycoplasma pneumoniae: Atypical Pathogen in Community Acquired Pneumonia. J Pure Appl Microbiol. 2020;14(4):2265-2276. doi: 10.22207/JPAM.14.4.04

(C) The Author(s) 2020. Open Access. This article is distributed under the terms of the Creative Commons Attribution 4.0 International License which permits unrestricted use, sharing, distribution, and reproduction in any medium, provided you give appropriate credit to the original author(s) and the source, provide a link to the Creative Commons license, and indicate if changes were made. 


\section{INTRODUCTION}

The class of Mollicutes has 200 known species. Sixteen of these species are of human source; others belong to creatures and plants. Four species have essential significance in human which are: Mycoplasma pneumoniae causing pneumonia and joint infection. Mycoplasma hominis now and again proceeds baby blues fever and uterine cylinder diseases. Ureaplasma urealyticum causes nongonococcal urethritis in males and is related with pulmonary ailment in low birth weight newborns. Mycoplasma genitalium is firmly identified with $M$. pneumoniae imputing with urogenital diseases. Different Mycoplasma are pathogenic to the respiratory, urogenital tracts and joints of people ${ }^{1}$.

M. pneumoniae, was first found in $1944^{2}$ termed as the Eaton operator. The small specialist couldn't be developed on standard bacteriologic media. Along these lines, it was initially thought to be an infection culturing that agent on a suitable medium suggesting the nowadays taxonomic nomenclature ${ }^{3,4,5}$.

M. pneumoniae is a mellow illness and is one of the basic reasons for respiratory tract diseases. It is a significant reason for community acquired pneumonia (CAP) and atypical pneumonia which is liable for mortality among children and adults ${ }^{6}$. The M. pneumoniae disease may be asymptomatic. It may cause genuine pneumonitis, hemolytic iron deficiency or an assortment of conceivable skin injuries ${ }^{1}$. M. pneumoniae pneumonia (MPP) is generally termed "walking pneumonia" due to the assumed kind. M. pneumoniae infection general mortality is low, up to $30 \%$, particularly amongst old people ${ }^{78}$. Side effects, pneumonia seriousness and research facility were comparable paying little heed to macrolide resistance ${ }^{9-11}$ which may progressively lead to troublesome treatment ${ }^{12}$.

M. pneumoniae is the smallest microorganisms which can live independently in the world self-replicating on laboratory media. It is a pathogen between the microorganism and the virus in the respiratory system ${ }^{13}$. It has a little diameter (length of 1-2 $\mu \mathrm{m}$ and width of 0.1-0.2 $\mu \mathrm{m}$ ). So, light microscopy can't recognize mycoplasmas ${ }^{14}$ as the colonies diameter is below $100 \mu \mathrm{m}^{15}$. Mycoplasmas size is $125-250 \mathrm{~nm}$ and its shape is pleomorphic due to the fact they lack an inflexible cell wall as a "unit membrane" of 3 layers that includes a sterol. So, serum or cholesterol producing sterol must be added to the medium and they grow on agar producing colony whose center is generally fixed underneath the agar. Mycoplasmas affect human cell membranes and can be inhibited by its specific antibody ${ }^{1}$. They are penicillin resistant as the mode of action of penicillin is through inhibiting cell wall synthesis lacked in our organism. However, they are susceptible to tetracycline or erythromycin. M. pneumoniae genome comprises of 687 genes. As a result of that little genetic material, the life form was constrained in the capacities and unfit to incorporate inflexible cell wall. Then again, sterols offer a support in the cell membrane. Therefore, these life forms are uncaring toward $\beta$-lactams, and are unstained by the gram staining strategy. M. pneumoniae reproduces by means of binary fission with well-organized chromosome method. A specific cell organelle, that is liable for cytadherence copies before cell division ${ }^{16-18}$.

\section{Epidemiology}

The infection rate might be high in case of close contact among children and young adults (50-90\%), but with variable frequency of pneumonitis $(3-30 \%)^{1}$. Roughly $25 \%$ of patients had $M$. pneumoniae extra pulmonary signs ${ }^{19}$ Pneumonia is a significant indication of $M$. pneumoniae disease, as $M$. pneumoniae represents $10-40 \%$ of CAP cases \{acute contamination of respiratory parenchymal tissue that is procured from the community enveloping patients who have not been hospitalized and not presented to any human services system\}. The revealed occurrence of irregular M. pneumoniae in adults varied from $4 \%$ to $8 \%$ of CAP which may raise during epidemics to $70 \% \%^{12,20,21}$ and in immunocompromised Egyptian infants represented $11.1 \%$ MPP hospitalization rate within the adults in the USA is around 100,000 hospitalizations annually. MPP stays undiagnosed due to its assumed nature, absence of demonstrative tests with great affectability and particularity and different diseases that either exist together or emulate $M$. pneumoniae ${ }^{12}$. Japanese examinations have shown a relationship of $M$. pneumoniae diseases with atmosphere changes, particularly with raised environmental temperatures and dampness during summer months. One examination demonstrated that 
each raise of $1^{\circ} \mathrm{C}$ leads to $17 \%$ expansion in MPP patients and $1 \%$ raise in moisture leads to $4 \%$ expansion ${ }^{23}$.

During the mid of year 2000 in Jaban, macrolide-resistant $M$. pneumoniae (MRMP) was first opserved and then extended to North America and Asia ${ }^{12}$. The pattern of MRMP is practically $90 \%$ of strains in the far east ${ }^{24,25}$. In Europe, MRMP showed $1 \%$ in Slovenia, the Netherlands and $30 \%$ in Italy ${ }^{26,27}$. MRMP represents around $10 \%$ in Canada and the USA of M. pneumoniae infections $\mathrm{s}^{28-30}$. Many investigations recommend that the high administration of macrolides might be answerable for MRMP ${ }^{31-33}$ as macrolides represent $30 \%$ of every oral antibiotics recommended in the nation $^{34}$. Up till now CAP is viewed as an intense illness, as it is the eighth reason for death in the USA, prompting extraordinary number of yearly deaths among children, which may reach up to 60,000 death $^{35}$. Recently, resistance to macrolides quickly increased around the world, mostly in East Asia that was first found in Asia ${ }^{36}$ and have expanded to China (90\%-100\%), Japan (87\%) and Korea $(84.6 \%)^{36-38}$. In Europe and North America, MRMP was, $26 \%$ in Italy, $19 \%$ in Scotland and $13 \%$ in the United States ${ }^{12,39}$.

\section{Pathogenesis}

M. pneumoniae cause CAP which is additionally called atypical pneumoniae or strolling pneumonia. This sort of pneumonia is viewed as atypical because of the way that the cells causing the disease are impervious to penicillin, the medication that is ordinarily used to treat pneumonia. Direct damage of epithelial cells or the human resistant reaction leads to the M. pneumoniae diseases pathogenicity ${ }^{40}$. Toxic molecules are released (i.e., CARDS [communityacquired respiratory distress syndrome] toxin which is a pertussis toxin-like protein) as a result of airways attachment of $M$. pneumoniae to surfaces of epithelial cells ${ }^{41}$.

Occurring of pathogenicity starts as the organism attaches to the tissue of the host. Then, M. pneumoniae digests glycerol releasing $\mathrm{H}_{2} \mathrm{O}_{2}$ and superoxide causing cilia and epithelial cells damage. The impacts of $\mathrm{H}_{2} \mathrm{O}_{2}$ on host cells as red blood cells, incorporate hemoglobin denaturation, lipids peroxidation, and inevitable cell death. The oxidation effect in the pulmonary epithelium causes cilia disintegration ${ }^{42-45}$.
From several investigations, MRMP has been associated with a more slow decrease in bacterial count, persevering side effects, for example, pneumonia, long hospital stay duration and extra-pulmonary manifestations resulting in change of antibiotic ${ }^{46,47}$. Also, other studies have identified infections of $M$. pneumoniae with asthma, and evidence indicates that $M$. pneumoniae may induce a bronchial system Th2 immune response ${ }^{48}$.

\section{Virulence Factors}

The attachement of $M$. pneumoniae to epithelial cells is very important for pathogenicity. The requirement for cytadherence is to get admission to neutrients from the host immune response and would additionally develop escaping from the immune system of the host. $M$. pneumoniae is adhered to the surface of epithelial cells as a result of proteins altration by surface sialic acid and sulfated glycolipids. Binding is essentially desired to cause our microorganism motility on host cell surfaces, a feature associated with cell growth and pervasion of infection ${ }^{49}$. The most significant characteristic destructiveness elements of $M$. pneumoniae incorporate cytoadherence. P30 and P1 are the primary grapple proteins which empower binding and are attached to $M$. pneumoniae terminal polar organelle. Unfavorable results of MPP is an ADPribosyltransferase exotoxin termed CARDS poison. They are critical harmfulness impacts producing cells ciliostasis and vacuolation. Cytotoxicity results from CARDS poison is additionally leads to free radicals creation ${ }^{41,50}$.

\section{Mode of transmission and susceptibility}

Direct contact is the main mode of transmission of $M$. pneumoniae. Also, secretions from the nose and throat of the infected patients when they cough or sneeze transmit $M$. pneumoniae and infection requires prolonged close contact with an infected person ${ }^{51}$. Elderly over 65 years, children around 2 years, immunocompromised patients whose take immunosuppressive therapy, patients with socioeconomic status and overcrowding 52 and patients with respiratory illnesses are risked to the disease ${ }^{21}$. Heavy smokers can reach up to 50 to $400 \%{ }^{53}$. Old ages have less MRMP than kids and teenagers, depending on macrolides regular $u \mathrm{e}^{54}$. However, majority is seen within elderly, so it is a cornerstone among velocity contrast on 
sickness ${ }^{21}$. Mycoplasma infection is most frequent in late summer as lengthy as 1-3 weeks ${ }^{55}$.

\section{Clinical Manifestations}

Pneumonia triggered through $M$. Pneumoniae is a self-limited illness, causing direct harm of the lung airlines and inflammatory reaction ${ }^{56}$. Patients having ordinary or slightly raised absolute leukocyte and neutrophil counts and low C-reactive protein degrees, have CAP without $M$. pneumoniae infection. However, patients having CAP with the organism have less leukocyte and neutrophil counts ${ }^{12,57}$.

A dry cough evolves to a wet cough within 4 days in acute infection and unusual pneumonia is the essential symptom detected in patients. The delayed onset of pharyngitis, sinus obstruction, uncommon otitis media, and ultimately extended lower respiration participation of pneumonia with low-grade fever and respiratory insinuates are the characterizations of the syndrome. Three weeks or slightly less are the incubation period previous to symptom development ${ }^{58,59}$. There can also be moderate leukocytosis, however the entire white blood count does no longer regularly exceed $15,000 / \mu \mathrm{L}$. Pneumonia signs and symptoms may additionally require approval to the scientific institution as blood oxygen is decreased and breathing is increased. Computed tomography (CT) is the useful choice detecting opacification of the air-space, thickening of bronchovascular cells, nodular leakage, and linear opaqueness. However, images of MPP cannot differentiate between bacterial or viral pneumonia ${ }^{60,61}$. M. pneumoniae develops cough for more than five days in teens and adults and can remain in adults following acute infection due to CARDS toxin presence ${ }^{62}$.

\section{M. pneumonia and asthma}

M. pneumoniae can be associated with allergies $^{63,64}$. This microorganism can be isolated from asthmatics ${ }^{48}$ having pneumonia episode according to CAP and $M$. pneumoniae infection had been detected by other investigations being before the asthmatic illness by unknown mechanism ${ }^{65,63}$. Immunoglobin (Ig)E response is the causative agent of that pathogenesis. A greater Ig response than that against bronchial asthma could also be produced according to other studies ${ }^{64,66}$. T lymphocytes affect the bronchial asthma disease with elevated level of $M$. pneumoniae patients serum interleukin (IL)-4 and (IL)-567,68. (Ig)E is motivated to be produced by such cytokines and mediated against P1 protein polypeptide playing an important role in bronchial asthma. So, $M$. pneumoniae is an allergen that induce $\mathrm{P} 1$-specific (Ig)E production ${ }^{69}$. As (Ig)E attached to mast cells interacts with $M$. pneumoniae, leading to release of histamine and inflammatory mediators ${ }^{70}$. A study performed by Dimitri and Gian, assumed that the high production of (Ig)E may lead to M. pneumoniae extrapulmonary disorders ${ }^{71,72}$ and children infected with $M$. pneumoniae extrapulmonary manifestations have elevated serum (Ig)E level ${ }^{72}$. History of asthma is more associated with refractory M. pneumoniae (disease with prolonged fever and delayed treatment) in children than without and require steroid therapy in order to diminish vascular endothelial growth factor (VEGF) ${ }^{73}$.

\section{Extrapulmonary Manifestations}

Extrapulmonary manifestations are associated with MRMP than with macrolidesensitive $M$. pneumoniae ${ }^{74}$ and may occur as a result of delayed effective treatment of $M$. pneumoniae either, it is macrolide resistant or sensitive $^{75}$. Also, extrapulmonary disorders can predict $M$. pneumoniae virus coinfection as Adenovirus infecting children less than 3 years ${ }^{76}$. These manifestations include skin, nervous, musculoskeletal, renal, cardiovascular, digestive and hematological systems ${ }^{77}$. As $M$. pneumoniae is able to penetrate the epithelial cell membrane of the respiratory system, as well as, spreading outside the respiratory system developing different manifestations ${ }^{78}$. M. pneumoniae may cause autoimmune hemolytic anemia as a result of changing red blood cells (RBCs) membranes antigenicity producing autoantibody. Also, common antigens shared between glycolipids of M. pneumoniae membrane and the heart, brain and lung tissues, causes the extrapulmonary manifestations resulting in host immune response associated with T-lymphocyte function disturbance, leukocytosis and intravascular clotting ${ }^{79}$. Extrapulmonary disorders are common in children and may include alteration of liver functions developing acute hepatitis ${ }^{80}$. Also, may include dermatological manifestations such as vesicular rashes, Stevens-Johnson syndrome and erythematous maculopapular ${ }^{77,81}$. The probability of extrapulmonary manifestations is increased 
in case of young people having $C A P^{55}$. Out of 152 children having CAP, 44 (28.9\%) were $M$. pneumonia positive, and out of these children, 10 $(22.7 \%)$ had mucocutaneous lesions ${ }^{82}$. After 2-14 days of respiratory illness, CNS problems include, meningitis, encephalitis, Guillain-Barre syndrome and optic neuritis ${ }^{83}$.

\section{Diagnosis}

Culture is now not used for activities analysis due to the fact it is laborious requiring unique enriched media with incubation duration up to 21 days. Therefore, bacterial cultures are generally time-consuming ${ }^{55}$. Pleuropneumonialike organisms (PPLO) stock containing tubes were vortexed, the swab was disposed of, the substance went through $0.45 \mathrm{~mm}$ channels and immunized in sterile PPLO stock and brooded under microaerophilic conditions $\left(5-10 \% \mathrm{CO}_{2}\right)$ at $37^{\circ} \mathrm{C}$ until indications of Mycoplasma development were watched. The development of Mycoplasma spp. is demonstrated by a shading change to yellow or orange, in light of corrosive maturation of glucose. At that point, when this shading changed, $500 \mathrm{~mL}$ of the stock medium was subcultured on PPLO agar plate and hatched inside about a month. Following 14 days of hatching, agar plates were watched utilizing a transformed magnifying lens, at 400 amplification for the perception of Mycoplasma provinces. Further biochemical portrayal was performed utilizing hemadsorption and hemolysis tests ${ }^{84}$.

M. pneumonia infections can be difficultly diagnosed due to the fact that mycoplasmas have not a cell wall so, can not be seen by Gram staining method. About $75 \%$ of patients with MPP have a titer of cold agglutinin more than 1:32 at the 2 nd week and limited after 6 to 8 weeks. If patient had cold agglutinin titer more than 1:64, the possibilty of having M. pneumonia infection was great ${ }^{12}$.

Some laboratory methods used to diagnose pneumonia include

Standard polymerase chain reaction (PCR) is the technique of choice. M. pneumoniae infection will become undetectable via PCR quicker than by way of serological evaluation as soon as antibiotic sensetivity is initiated ${ }^{12}$.

Chest radiography is the most important diagnostic imaging for $\mathrm{CAP}^{85}$. The radiographic presentation of "atypical" pneumonia due to M. pneumoniae is extraordinarily variable. Bilateral, diffuse interstitial infiltrates are common, pleural effusions can occur, however none of the radiographic findings related with $M$. pneumonia CAP are specific ${ }^{86}$.

Estimating complete blood count (CBC), blood urea nitrogen, white blood cell count and serum creatinine to be utilized in seriousness scoring of the illness ${ }^{87}$.

Tests for specific antigens or antibodies blood culture. \{ Blood culture is definitely not a routine indicative test of CAP cases and is prescribed to those with serious CAP ${ }^{85}$.

Serology (fourfold rise in IgG or IgM) ${ }^{1}$.

The utilization of various provocative biomarkers in the evaluation of patients with CAP like C-receptive protein (CRP) levels and procalcitonin, could foresee the bacterial etiology for CAP and help to keep away from the maltreatment of anti-microbial agents ${ }^{88}$.

A 4-fold change in titers after some time could be used for immunological determination (IgM titers rise before IgG antibodies). After16 days of manifestations, IgM measures increments with the span of indications, moving toward over $70 \%$. The prescient IgM estimation was about $80 \%{ }^{89}$.

Table 1. M. pneumoniae extrapulmonary diseases reported in children ${ }^{78}$

\begin{tabular}{|c|c|}
\hline System & Disease \\
\hline Skin & Unspecific rashes \& Hives \\
\hline Neurologic & $\begin{array}{l}\text { Early-onset encephalitis/myelitis, Aseptic Meningitis. } \\
\text { Late-onset Encephalitis/myelitis GBS, Cerebellitis, Stroke. }\end{array}$ \\
\hline Musculoskeletal & Arthritis, Myositis \\
\hline renal & Nephritis \\
\hline digestive & Acute hepatitis, Acute pancreatitis \\
\hline hematological & Hemolytic anemia, Thrombocytopenia, Thrombosis \\
\hline Cardiovascular & Pericarditis, Myocarditis, Endocarditis \\
\hline
\end{tabular}


Agar-and broth in vitro testing method was laborious. So, PCR methods could alternatively detect $23 \mathrm{~S}$ rRNA region point mutations in respiratory samples as a macrolide resistance marker.

Normal reasons for CAP, notwithstanding M. pneumoniae, incorporate Legionella pneumophila, Streptococcus pneumoniae, Chlamydia pneumoniae, flu AH1N1 and Haemophilus influenzae. Recently, SARS CoV2, SARS, flu infection (H1N1), avian influenza (H5N1), and MERS-CoV have developed to as the basic pathogens to cause serious pandemic CAP. So, the acknowledgment of the signs and side effects is significant. Sputum assessment, blood culture, and different tests dictate the causative living beings ${ }^{19,91}$. Recently, an Egyptian examination has uncovered atypical bacterial disease and was analyzed in $13.3 \%$ of cases, at that point Klebsiella pneumoniae was $10.37 \%$. Streptococcus pneumoniae and Pseudomonas aeruginosa were $7.78 \%{ }^{92}$. An examination in Zagazig college Pediatric clinic was performed to clarify the regular bacterial pathogens causing CAP among immunocompetent newborn children and preschool kids. Forty eight cases were examined. Infants having 1-72 months old gave indications of pneumonia as per world and health organization (WHO). All patients were exposed to the accompanying: data assortment, chest $x$-beam, blood culture, routine lab examination and sputum investigation. Immunofluoresent method detected (Ig) $M$ antibodies against basic respiratory pathogens. By serological results, age in case of viral pneumonia was significant and was non-significant in case of bacterial pneumonia. Legionella pneumophila (33.33\%) represented a causative organism and $M$. Pneumoniae represented $6.25 \%{ }^{93}$.

Treatment of Mycoplasma pneumonia infection: Penicillin, cephalosporins and vancomycin are insufficient. In the treatment of $M$. pneumonia; antimicrobials against $M$. pneumoniae are bacteriostatic, not bactericidal and act on the ribosome of bacteria to hinder synthesis of protein such as, erythromycin. Those that inhibit DNA replication, for example, fluoroquinolones are exceptionally successful. Macrolides are generally viewed as the principal antimicrobials for $M$. pneumoniae CAP in kids on the grounds that the other options (for example fluoroquinolones) are not affirmed for use in the principal long periods of life ${ }^{94}$. The utilization of macrolides with steroids has been suggested in serious instances of MPP ${ }^{95}$. Ketolides with macrolides explicit 235 rRNA nucleotides in the 50 s subunit of ribosome, inhibiting synthesis of protein as they separate peptidyl-tRNA ${ }^{12,96}$. Macrolides appear to adjust or direct the insusceptible cell by hindering provocative cell chemotaxis, cytokine synthesis, responsive oxygen species creation and intracellular flagging pathways. Azithromycin is better than different macrolides, as it has more half-life than other macrolides, taking into account a shorter treatment duration. Also, fluoroquinolones are successful, having more MICs and consider as second line treatment for children $^{54,97}$. Patients with CAP should proceed with antimicrobial treatment for at least 5 days; 7-10 days is typically sufficient ${ }^{98}$ and antibiotic treatment could reach out to 14 days ${ }^{85}$.

Advantages and Disadvantages of tetracyclines (TCS) and fluoroquinolones (FQs)

TCs and FQs advantages are lowering of manifestations with quick effect ${ }^{54}$; however, they have numerous problems. Antibiotic medications are promptly bound to calcium saved in recently shaped bone or teeth in small kids. At the point when an antibiotic medication is given during pregnancy, it tends to be stored in the fetal teeth, prompting fluorescence, staining, and finish dysplasia. It can likewise be stored in bone, where it might cause deformation. If the medication is given to young age more than 8 years, comparable changes can result ${ }^{99}$. Thus, these medications have not been suggested as first-line operators for patients under 18 years old ${ }^{99}$.

A second-generation TC as doxycycline has less calcium binding, prompting decreased danger of staining of teeth finishing hypoplasia ${ }^{100,101}$. Four $\mathrm{mg} / \mathrm{kg} /$ day doxycycline was used for treatment for 10 days in 2-7 years asthmatic children ${ }^{102} 2.3 \mathrm{mg} /$ $\mathrm{kg} /$ day was used for 7 days in 0.2-7.9 years kids having rhabdomyosarcoma (RMS) ${ }^{103}$ and 12.5 days treatment by $10 \mathrm{mg} / \mathrm{kg} /$ day in less than 8 years old kids having CNS disorders ${ }^{104}$. However, staining of teeth was watched $(2.8 \%)$ in grown-ups getting courses of doxycycline (100 mg twice day by day for a half year) for stomach aortic aneurysms ${ }^{105}$. Jungle fever chemoprophylaxis by doxycycline could 
increase the danger of developing impervious bacteria to antimicrobials ${ }^{106}$.

Blanching with $\mathrm{H}_{2} \mathrm{O}_{2}$, crowns with high oral cleaning, staying away from daylight during treatment or vitamin $\mathrm{C}$ administration could prevent teeth staining ${ }^{107,108}$. Oftenly, unfavorable responses were developed with minocycline (3\%$6 \%$ of grown-up patients) ${ }^{109}$. However, minocycline is alternative when doxycycline is unavailable ${ }^{110}$.

Treatment of Macrolide Resistant M. pneumonia [MRMP]

Conversely, macrolides show up clinical successful in certain patients having MRMP; macrolides could be used for treating $30 \%$ of MRMP $^{9,10,117}$. As $M$. pneumonia infections are frequently self-limited, macrolides may lower the clinical side effects ${ }^{54}$. Until now, the main elective medicines for MRMP are fluoroquinolones (FQs), TCs or fundamental steroids. Because of the association of MRMP and teeth harm emerging from antibiotic medication use, fluoroquinolone/ tosufloxacin could be used as a second-line tranquilize in situations of MRMP during 2013$2015^{118}$. However, M. pneumoniae also, showed resistance to fluoroquinolones according to in vitro studies $^{119}$.

Oral antimicrobial agents can't be used for serious MRMP situations without serious consequences, minocycline can be utilized intravenously $(4 \mathrm{mg} / \mathrm{kg} /$ day on the primary day, followed by $2 \mathrm{mg} / \mathrm{kg}$ at regular intervals for a limit of $100 \mathrm{mg}$ ). Doxycycline is suggested as a first line treatment when advantages surpass dangers ${ }^{54}$. An another option, foundational corticosteroids have been utilized to decrease extra-or intrapulmonary signs ${ }^{54}$. Prednisolone gives off an impression of being the best corticosteroid in treatment of CAP, because it initiate platelet in vitro non-gnomically ${ }^{120}$. New antimicrobials, for example, lefamulin, solithromycin, nafithromycin, omadacycline and zoliflodacin are utilized to treat MRMP ${ }^{12}$.

\section{CONCLUSION}

M. pneumoniae diseases are critical and influence all age groups, particularly the young adults and children. More studies are needed to build up accessible method for fast finding. There is no immunization to $M$. pneumonia and future research is needed for immunization advancement.
Macrolide resistance was developed and might prompt delayed suitable antimicrobial treatment. Early determination of $M$. pneumoniae and the attention to macrolide resistance make early antimicrobial treatment conceivable and may improve clinical results.

\section{ACKNOWLEDGMENTS}

All listed authors are thankful to their representative university for providing the related support to compile this work.

\section{CONFLICT OF INTEREST}

The authors declare that there is no conflict of interest.

\section{AUTHORS' CONTRIBUTION}

All listed authors have made a substantial, direct, and intellectual contribution to the work, and approved it for publication.

\section{FUNDING}

None.

\section{ETHICS STATEMENT}

This article does not contain any studies with human participants or animals performed by any of the authors.

\section{DATA AVAILABILITY}

All datasets generated or analyzed during this study are included in the manuscript.

\section{REFERENCES}

1. Carroll KC, Butel J, Morse S. Jawetz Melnick \& Adelbergs Medical Microbiology 27 E. McGraw-Hill Education. 2015.

2. Eaton MD, Meiklejohn G, Van Herick W. Studies on the etiology of primary atypical pneumonia: A filterable agent transmissible to cotton rats, hamsters, and chick embryos. J Exp Med. 1944;79(6):649-668. doi:10.1084/ jem.79.6.649

3. R. S. Downloaded from nejm.org at Univ of Manitoba Libraries on February 10, 2013. For personal use only. No other uses without permission. From the NEJM Archive. Copyright (C) 2010 Massachusetts Medical Society. All rights res. N Engl J Med. 2010;313(18).

4. Gardner TB, Forsmark CE. Clinical features. Autoimmune Pancreat Cholangitis. 2013;9781441964(Mc):85-94. doi:10.1007/978-1-4419-6430-4_8

5. Chanock RM, Hayflick L, Barile MF. Growth on Artificial Medium of an Agent Associated With Atypical Pneumonia and Its Identification As a Pplo. Proc Natl Acad Sci. 1962;48(1):41-49. doi:10.1073/pnas.48.1.41

6. Ranjbar R, Halaji M. Epidemiology of Mycoplasma 
pneumoniae prevalence in Iranian patients: a systematic review and meta-analysis. J Med Microbiol. 2019;68(11):1614-1621. doi:10.1099/jmm.0.001079

7. Niederman MS, Brito V. Pneumonia in the older patient. Clin Chest Med. 2007;28(4):751-771. doi: 10.1016/j.ccm.2007.08.004

8. Khoury T, Sviri S, Rmeileh AA, et al. Increased rates of intensive care unit admission in patients with Mycoplasma pneumoniae: a retrospective study. Clin Microbiol Infect. 2016;22(8):711-714. doi: 10.1016/j.cmi.2016.05.028

9. Matsubara K, Morozumi M, Okada T, et al. A comparative clinical study of macrolidesensitive and macrolide-resistant Mycoplasma pneumoniae infections in pediatric patients. $J$ Infect Chemother. 2009;15(6):380-383. doi: 10.1007/s10156-009-0715-7

10. Cardinale F, Chironna M, Chinellato I, Principi $\mathrm{N}$, Esposito S. Clinical relevance of Mycoplasma pneumoniae macrolide resistance in children. J Clin Microbiol. 2013;51(2):723-724. doi: 10.1128/ JCM.02840-12

11. Wu P, Chang L, Lin $\mathrm{H}$, et al. Epidemiology and clinical manifestations of children with macrolide-resistant Mycoplasma pneumoniae pneumonia in Taiwan. Pediatr Pulmonol. 2013;48(9):904-911. doi: 10.1002/ ppul.22706

12. Waites KB, Xiao L, Liu Y, Balish MF, Atkinson TP. Mycoplasma pneumoniae from the respiratory tract and beyond. Clin Microbiol Rev. 2017;30(3):747-809. doi: 10.1128/CMR.00114-16

13. Zhou L, Wang W, Peng X, et al. Clinical features of Mycoplasma pneumoniae infection in respiratory tract in children in middle south of China. Eur J Inflamm. 2018;16:01-05. doi:10.1177/2058739218772246

14. Waites KB, Talkington DF. Mycoplasma pneumoniae and its role as a human pathogen. Clin Microbiol Rev. 2004;17(4):697-728. doi:10.1128/CMR.17.4.697728.2004

15. Himmelreich R, Hubert $H$, Plagens $H$, Pirkl E, Li BC, Herrmann R. Complete sequence analysis of the genome of the bacterium Mycoplasma pneumoniae. Nucleic Acids Res. 1996;24(22):44204449. doi:10.1093/nar/24.22.4420

16. Krause DC, Balish MF. Cellular engineering in a minimal microbe: Structure and assembly of the terminal organelle of Mycoplasma pneumoniae. Mol Microbiol. 2004;51(4):917-924. doi:10.1046/j.13652958.2003.03899.x

17. Balish MF. Subcellular structures of mycoplasmas. Front Biosci. 2006;11:2017-2027. doi: 10.2741/1943

18. Balish MF, Krause DC. Mycoplasmas: a distinct cytoskeleton for wall-less bacteria. J Mol Microbiol Biotechnol. 2006;11(3-5):244-255. doi: 10.1159/000094058

19. Frantz GF, McAninch SA. Mycoplasma Mucositis. 2018.

20. Jacobs E, Ehrhardt I, Dumke R. New insights in the outbreak pattern of Mycoplasma pneumoniae. Int J Med Microbiol. 2015;305(7):705-708. doi: 10.1016/j. ijmm.2015.08.021

21. Shaaban LH. Dilemma of community-acquired pneumonia. Egypt J Chest Dis Tuberc. 2019;68(1):1.
22. El Seify MY, Fouda EM, Ibrahim HM, et al. Microbial etiology of community-acquired pneumonia among infants and children admitted to the pediatric hospital, Ain Shams University. Eur J Microbiol Immunol. 2016;6(3):206:214. doi:10.1556/1886.2016.00022

23. Onozuka D, Hashizume $M$, Hagihara A. Impact of weather factors on Mycoplasma pneumoniae pneumonia. Thorax. 2009;64(6):507-511. doi: 10.1136/thx.2008.111237

24. Spuesens EBM, Meijer A, Bierschenk D, et al. Macrolide resistance determination and molecular typing of Mycoplasma pneumoniae in respiratory specimens collected between 1997 and 2008 in The Netherlands. J Clin Microbiol. 2012;50(6):1999-2004. doi: 10.1128/ JCM.00400-12

25. Okazaki N, Ohya H, Sasaki T. Mycoplasma pneumoniae isolated from patients with respiratory infection in Kanagawa Prefecture in 1976-2006: emergence of macrolide-resistant strains. Jpn J Infect Dis. 2007;60(5):325.

26. Averbuch D, Hidalgo-Grass C, Moses AE, Engelhard D, Nir-Paz R. Macrolide resistance in Mycoplasma pneumoniae, Israel, 2010. Emerg Infect Dis. 2011;17(6):1079-1082. doi: 10.3201/eid/1706.101558

27. Mrvic T, Praprotnik M, Kese D. Prevalence, genotyping and macrolide resistance of Mycoplasma pneumoniae among isolates of patients with respiratory tract infections, Central Slovenia, 2006 to 2014. Eurosurveillance. 2015;20(37). doi: 10.2807/15607917.ES.2015.20.37.30018

28. Diaz MH, Benitez AJ, Winchell JM. Investigations of Mycoplasma pneumoniae infections in the United States: trends in molecular typing and macrolide resistance from 2006 to 2013. J Clin Microbiol. 2015;53(1):124-130. doi: 10.1128/JCM.02597-14

29. Eshaghi A, Memari N, Tang P, et al. Macrolide-resistant Mycoplasma pneumoniae in humans, Ontario, Canada, 2010-2011. Emerg Infect Dis. 2013;19(9):1525-1527. doi: 10.3201/eid1909.121466

30. Zheng X, Lee S, Selvarangan R, et al. Macrolideresistant mycoplasma pneumoniae, United States. Emerg Infect Dis. 2015;21(8):1470-1472. doi: 10.3201/ eid2108.150273

31. Nilsson AC, Jensen JS, Bjorkman P, Persson K. Development of macrolide resistance in Mycoplasma pneumoniae-infected Swedish patients treated with macrolides. Scand J Infect Dis. 2014;46(4):315-319. doi: 10.3109/00365548.2013.866268

32. Chironna M, Sallustio A, Esposito S, et al. Emergence of macrolide-resistant strains during an outbreak of Mycoplasma pneumoniae infections in children. J Antimicrob Chemother. 2011;66(4):734-737. doi: 10.1093/jac/dkr003

33. Ferguson GD, Gadsby NJ, Henderson SS, et al. Clinical outcomes and macrolide resistance in Mycoplasma pneumoniae infection in Scotland, UK. J Med Microbiol. 2013;62(12):1876-1882. doi: 10.1099/jmm.0.0661910

34. Okada T, Morozumi M, Tajima T, et al. Rapid effectiveness of minocycline or doxycycline against macrolide-resistant Mycoplasma pneumoniae infection in a 2011 outbreak among Japanese children. 
Clin Infect Dis. 2012;55(12):1642-1649. doi: 10.1093/ $\mathrm{cid} / \mathrm{cis} 784$

35. Broulette J, Yu H, Pyenson B, Iwasaki K, Sato R. The incidence rate and economic burden of communityacquired pneumonia in a working-age population. $A m$ Heal drug benefits. 2013;6(8):494.

36. Hong KB, Choi EH, Lee HJ, et al. Macrolide resistance of Mycoplasma pneumoniae, South Korea, 2000-2011. Emerg Infect Dis. 2013;19(8):1281-1284. doi: 10.3201/ eid1908.121455

37. Yoon IA, Hong KB, Lee $\mathrm{HJ}$, et al. Radiologic findings as a determinant and no effect of macrolide resistance on clinical course of Mycoplasma pneumoniae pneumonia. BMC Infect Dis. 2017;17(1):402. doi: 10.1186/s12879-017-2500-z

38. Yamazaki T, Kenri T. Epidemiology of Mycoplasma pneumoniae infections in Japan and therapeutic strategies for macrolide-resistant $M$. pneumoniae. Front Microbiol. 2016;7:693. doi: 10.3389/ fmicb.2016.00693

39. Pereyre S, Goret J, Bebear C. Mycoplasma pneumoniae: current knowledge on macrolide resistance and treatment. Front Microbiol. 2016;7:974. doi: 10.3389/ fmicb.2016.00974

40. Jeong JE, Soh JE, Kwak JH, et al. Increased procalcitonin level is a risk factor for prolonged fever in children with Mycoplasma pneumonia. Korean J Pediatr. 2018;61(8):258-263. doi: 10.3345/kjp.2018.61.8.258

41. Kannan TR, Taylor AB, Pakhomova ON, et al. Structure of CARDS toxin, a unique ADP-ribosylating and vacuolating cytotoxin from Mycoplasma pneumoniae. Proc Natl Acad Sci. 2015;112(16):5165-5170. doi: 10.1073/pnas.1420308112

42. Somerson NL, Walls BE, Chanock RM. Hemolysin of Mycoplasma pneumoniae: tentative identification as a peroxide. Science. 1965;150(3693):226-228. doi: 10.1126/science.150.3693.226

43. Low IE. Effect of medium on $\mathrm{H}_{2} \mathrm{O}_{2}$ levels and peroxidaselike activity by Mycoplasma pneumoniae. Infect Immun. 1971;3(1):80-86. doi: 10.1128/IAI.3.1.8086.1971

44. Tryon VV, Baseman JB. The acquisition of human lactoferrin by Mycoplasma pneumoniae. Microb Pathog. 1987;3(6):437-443. doi: 10.1016/08824010(87)90013-1

45. Chris Minion F, Jarvill-Taylor K. Membrane-associated hemolysin activities in mycoplasmas. FEMS Microbiol Lett. 1994;116(1):101-106. doi: 10.1111/j.15746968.1994.tb06682.x

46. Kawai Y, Miyashita N, Yamaguchi T, et al. Clinical efficacy of macrolide antibiotics against genetically determined macrolide-resistant Mycoplasma pneumoniae pneumonia in paediatric patients. Respirology. 2012;17(2):354-362. doi: 10.1111/j.14401843.2011.02102.x

47. Zhou Y, Zhang Y, Sheng Y, Zhang L, Shen Z, Chen Z. More complications occur in macrolide-resistant than in macrolide-sensitive Mycoplasma pneumoniae pneumonia. Antimicrob Agents Chemother. 2014;58(2):1034-1038. doi: 10.1128/AAC.01806-13

48. Smith-Norowitz TA, Silverberg JI, Kusonruksa M, et al. Asthmatic Children Have Increased Specific Anti-
Mycoplasma pneumoniae IgM but not IgG or IgEValues Independent of History of Respiratory Tract Infection. Pediatr Infect Dis J. 2013;32(6):599-603. doi: 10.1097/INF.0b013e3182862ea8

49. Prince OA, Krunkosky TM, Krause DC. In vitro spatial and temporal analysis of mycoplasma pneumoniae colonization of human airway epithelium. Infect Immun. 2014;82(2):579-586. doi:10.1128/IAI.0103613

50. Hardy RD, Coalson JJ, Peters J, et al. Analysis of pulmonary inflammation and function in the mouse and baboon after exposure to Mycoplasma pneumoniae CARDS toxin. PLOS ONE. 2009;4(10). doi: 10.1371/journal.pone.0007562

51. Miyashita N, Kawai $\mathrm{Y}$, Akaike H, Teranishi H, Ouchi $\mathrm{K}$, Okimoto N. Transmission of macrolide-resistant Mycoplasma pneumoniae within a family. J Infect Chemother. 2013;19(6):1196-1201. doi:10.1007/ s10156-013-0604-y

52. Yu Y, Fei A. Atypical pathogen infection in communityacquired pneumonia. Biosci Trends. 2016;10(1):7-13. doi: 10.5582/bst.2016.01021

53. Baik I, Curhan GC, Rimm EB, Bendich A, Willett WC, Fawzi WW. A prospective study of age and lifestyle factors in relation to community-acquired pneumonia in US men and women. Arch Intern Med. 2000;160(20):3082-3088. doi: 10.1001/ archinte.160.20.3082

54. Yang HJ. Benefits and risks of therapeutic alternatives for macrolide resistant Mycoplasma pneumoniae pneumonia in children. Korean J Pediatr. 2019;62(6):199-205. doi:10.3345/kjp.2018.07367

55. Meyer Sauteur PM, Unger WWJ, Van Rossum AMC, Berger C. The Art and Science of Diagnosing Mycoplasma pneumoniae Infection. Pediatr Infect Dis J. 2018;37(11):1192-1195. doi:10.1097/ INF.0000000000002171

56. Babaei Z, Pouladi I, Ashtari A, Azimi G, Niakan M. The prevalence of atypical pneumonia caused by mycoplasma pneumoniae (P1 gene) in patients with respiratory infections by culture and molecular PCR methods in Tehran, Iran. Jundishapur J Microbiol. 2019;12(11):e84174. doi: 10.5812/jjm.84174.

57. Fischer JE, Steiner F, Zucol F, et al. Use of simple heuristics to target macrolide prescription in children with community-acquired pneumonia. Arch Pediatr Adolesc Med. 2002;156(10):1005-1008. doi: 10.1001/ archpedi.156.10.1005

58. Nambu A, Saito A, Araki T, et al. Chlamydia pneumoniae: comparison with findings of Mycoplasma pneumoniae and Streptococcus pneumoniae at thin-section CT. Radiology. 2006;238(1):330-338. doi: 10.1148/ radiol.2381040088

59. Norisue $\mathrm{Y}$, Tokuda $\mathrm{Y}$, Koizumi M, Kishaba T, Miyagi S. Phasic characteristics of inspiratory crackles of bacterial and atypical pneumonia. Postgrad Med J. 2008;84(994):432-436. doi: 10.1136/ pgmj.2007.067389

60. Reittner P, Muller NL, Heyneman L, et al. Mycoplasma pneumoniae pneumonia: radiographic and highresolution CT features in 28 patients. Am J Roentgenol. 2000;174(1):37-41. doi: 10.2214/ajr.174.1.1740037 
61. Miyashita N, Sugiu T, Kawai $\mathrm{Y}$, et al. Radiographic features of Mycoplasma pneumoniae pneumonia: differential diagnosis and performance timing. $B M C$ Med Imaging. 2009;9(1):7. doi: 10.1186/1471-23429-7

62. Kannan TR, Coalson JJ, Cagle M, Musatovova O, Hardy $\mathrm{RD}$, Baseman JB. Synthesis and distribution of CARDS toxin during Mycoplasma pneumoniae infection in a murine model. J Infect Dis. 2011;204(10):1596-1604. doi: 10.1093/infdis/jir557

63. Biscardi S, Lorrot M, Marc E, et al. Mycoplasma pneumoniae and asthma in children. Clin Infect Dis. 2004;38(10):1341-1346. doi: 10.1086/392498

64. Wood PR, Hill VL, Burks ML, et al. Mycoplasma pneumoniae in children with acute and refractory asthma. Ann Allergy, Asthma Immunol. 2013;110(5):328-334. doi: 10.1016/j.anai.2013.01.022

65. Yano T, Ichikawa Y, Komatu S, Arai S, Oizumi K. Association of Mycoplasma pneumoniae antigen with initial onset of bronchial asthma. Am J Respir Crit Care Med. 1994;149(5):1348-1353. doi: 10.1164/ ajrccm.149.5.8173777

66. Atkinson TP, Duffy LB, Pendley D, Dai Y, Cassell $\mathrm{GH}$. Deficient immune response to Mycoplasma pneumoniae in childhood asthma. In: Allergy \& Asthma Proceedings. 2009;30(2):158:165. doi: 10.2500/ aap.2009.30.3207

67. Esposito S, Droghetti R, Bosis S, Claut L, Marchisio P, Principi N. Cytokine secretion in children with acute Mycoplasma pneumoniae infection and wheeze. Pediatr Pulmonol. 2002;34(2):122-127. doi: 10.1002/ ppul.10139

68. Jeong Y-C, Yeo M-S, Kim J-H, Lee H-B, Oh J-W. Mycoplasma pneumoniae infection affects the serum levels of vascular endothelial growth factor and interleukin-5 in atopic children. Allergy Asthma Immunol Res. 2012;4(2):92-97. doi: 10.4168/ aair.2012.4.2.92

69. Ye Q, Mao J hua, Shu Q, Shang S qiang. Mycoplasma pneumoniae induces allergy by producing P1-specific immunoglobulin E. Ann Allergy, Asthma Immunol. 2018;121(1):90-97. doi:10.1016/j.anai.2018.03.014

70. Gil JC, Cedillo RL, Mayagoitia BG, Paz MD. Isolation of Mycoplasma pneumoniae from asthmatic patients. Ann Allergy. 1993;70(1):23-25.

71. Poddighe $\mathrm{D}$, Marseglia GL. Is there any relationship between extra-pulmonary manifestations of Mycoplasma pneumoniae infection and atopy/ respiratory allergy in children? Pediatr Rep. 2016;8(1):4-5. doi:10.4081/pr.2016.6395

72. Poddighe D, Comi EV, Brambilla I, Licari A, Bruni P, Marseglia GL. Increased total serum immunoglobulin E in children developing mycoplasma pneumoniaerelated extra-pulmonary diseases. Iran I Allergy, Asthma Immunol. 2018;17(5):. doi:10.18502/ijaai. v17i5.307

73. Shin JE, Cheon BR, Shim JW, et al. Increased risk of refractory Mycoplasma pneumoniae pneumonia in children with atopic sensitization and asthma. Korean J Pediatr. 2014;57(6):271-277. doi:10.3345/ kjp.2014.57.6.271

74. Narita M, Tanaka H. Cytokines involved in the severe manifestations of pulmonary diseases caused by Mycoplasma pneumoniae. Pediatr Pulmonol. 2007;42(4):397. doi: 10.1002/ppul.20445

75. Yang T, Chang T, Lu C, et al. Mycoplasma pneumoniae in pediatric patients: Do macrolide-resistance and / or delayed treatment matter ? J Microbiol Immunol Infect. 2019;52(2):329-335. doi:10.1016/j. jmii.2018.09.009

76. Zhou Y, Wang J, Chen W, et al. Impact of viral coinfection and macrolide-resistant mycoplasma infection in children with refractory Mycoplasma pneumoniae pneumonia. BMC Infect Dis. 2020;20(1):633. doi:10.1186/s12879-020-05356-1

77. Guleria R, Nisar N, Chawla TC, Biswas NR. Mycoplasma pneumoniae and central nervous system complications: a review. J Lab Clin Med. 2005;146(2):55-63. doi: 10.1016/j.lab.2005.04.006

78. Poddighe Di. Extra-pulmonary diseases related to mycoplasma pneumoniae in children: Recent insights into the pathogenesis. Curr Opin Rheumatol. 2018;30(4):380-387. doi:10.1097/ BOR.0000000000000494

79. Shim JY. Current perspectives on atypical pneumonia in children. Clin Exp Pediatr. 2020:63(12);469-476. doi:10.3345/cep.2019.00360

80. Poddighe D. Mycoplasma pneumoniae-related hepatitis in children. Microb Pathog. 2020;139: 103863. doi:10.1016/j.micpath.2019.103863

81. Johnson S. Possible autoantibody complications in Mycoplasma pneumoniae infection. Clinical Infectious Diseases, 2006;43(10):1246. doi: 10.1086/508471

82. Sauteur PMM, Theiler $M$, Buettcher $M$, Seiler $M$, Weibel L, Berger C. Frequency and Clinical Presentation of Mucocutaneous Disease Due to Mycoplasma pneumoniae Infection in Children with Community-Acquired Pneumonia. JAMA Dermatology. 2020;156(2):144-150. doi:10.1001/ jamadermatol.2019.3602

83. Tsiodras S, Kelesidis I, Kelesidis T, Stamboulis E, Giamarellou H. Central nervous system manifestations of Mycoplasma pneumoniae infections. J Infect. 2005;51(5):343-354. doi: 10.1016/j.jinf.2005.07.005

84. Mohanty S, Singhal R, Sood S, Dhawan B, Kapil A, Das BK. Citrobacter infections in a tertiary care hospital in Northern India. J Infect. 2007;54(1):58-64. doi: 10.1016/j.jinf.2006.01.015

85. Mandell LA, Wunderink RG, Anzueto A, et al. Infectious Diseases Society of America/American Thoracic Society consensus guidelines on the management of community-acquired pneumonia in adults. Clin Infect Dis. 2007;44(Suppl 2):S27-S72. doi: 10.1086/511159

86. Harris M, Clark J, Coote N, et al. British Thoracic Society guidelines for the management of community acquired pneumonia in children: update 2011. Thorax. 2011;66(Suppl 2):ii1-ii23. doi: 10.1136/ thoraxjnl-2011-200598

87. Musher DM, Thorner AR. Community-acquired pneumonia. N Engl J Med. 2014;371(17):1619-1628. doi: 10.1056/NEJMra1312885

88. Kolditz M, Ewig S, Hoffken G. Management-based risk prediction in community-acquired pneumonia by scores and biomarkers. Eur Respir J. 2013;41(4):974- 


\section{4. doi: $10.1183 / 09031936.00104412$}

89. File TM, Segreti J, Dunbar L, et al. A multicenter, randomized study comparing the efficacy and safety of intravenous and/or oral levofloxacin versus ceftriaxone and/or cefuroxime axetil in treatment of adults with community-acquired pneumonia. Antimicrob Agents Chemother. 1997;41(9):1965-1972. doi: 10.1128/ AAC.41.9.1965

90. Herrero FS, Olivas JB. Microbiology and risk factors for community-acquired pneumonia. Semin Respir Crit Care Med. 2012;33(3):220-231. doi: 10.1055/s-00321315634

91. Lindenauer PK, Lagu T, Shieh M-S, Pekow PS, Rothberg MB. Association of diagnostic coding with trends in hospitalizations and mortality of patients with pneumonia, 2003-2009. JAMA. 2012;307(13):14051413. doi: 10.1001/jama.2012.384

92. El-Sokkary RH, Ramadan RA, El-Shabrawy M, et al. Community acquired pneumonia among adult patients at an Egyptian university hospital: Bacterial etiology, susceptibility profile and evaluation of the response to initial empiric antibiotic therapy. Infect Drug Resist. 2018;11:2141-2150. doi:10.2147/IDR.S182777

93. Hussein H, Azab S, .Esh A, Abdel Rhman H. Microbial Etiology of Community Acquired Pneumonia Among Infants and Children Admitted To Zagazig University Pediatric Hospital. Zagazig Univ Med J. 2019;25(6):809816. doi:10.21608/zumj.2019.10790.11210

94. Esposito S, Bosis S, Begliatti E, et al. Acute tonsillopharyngitis associated with atypical bacterial infection in children: natural history and impact of macrolide therapy. Clin Infect Dis. 2006;43(2):206-209. doi: $10.1086 / 505120$

95. Parrott GL, Kinjo T, Fujita J. A compendium for Mycoplasma pneumoniae. Front Microbiol. 2016;7:513. doi:10.3389/fmicb.2016.00513

96. Waites KB, Crabb DM, Duffy LB. Comparative in vitro susceptibilities of human mycoplasmas and ureaplasmas to a new investigational ketolide, CEM101. Antimicrob Agents Chemother. 2009;53(5):21392141. doi: 10.1128/AAC.00090-09

97. Bajantri B, Venkatram S, Diaz-Fuentes G. Mycoplasma pneumoniae : A Potentially Severe Infection . J Clin Med Res. 2018;10(7):535-544. doi:10.14740/jocmr3421w

98. File Jr TM, Mandell LA, Tillotson G, Kostov K, Georgiev O. Gemifloxacin once daily for 5 days versus 7 days for the treatment of community-acquired pneumonia: a randomized, multicentre, double-blind study. $J$ Antimicrob Chemother. 2007;60(1):112-120. doi: 10.1093/jac/dkm119

99. Katzung BG, Trevor AJ. Basic \& Clinical Pharmacology. McGraw-Hill Education New York. 2015.

100. Forti G, Benincori C. Doxycycline and the teeth. Lancet. 1969;1(7598):782. doi: 10.1016/S01406736(69)91787-5

101. Lambrou DB, Tahos BS, Lambrou KD. In vitro studies of the phenomenon of tetracycline incorporation into enamel. J Dent Res. 1977;56(12):1527-1532. doi: 10.1177/00220345770560122201

102. Volovitz B, Shkap R, Amir J, Calderon S, Varsano I, Nussinovitch M. Absence of tooth staining with doxycycline treatment in young children.
Clin Pediatr (Phila). 2007;46(2):121-126. doi: 10.1177/0009922806290026

103. Todd SR, Dahlgren FS, Traeger MS, et al. No visible dental staining in children treated with doxycycline for suspected Rocky Mountain spotted fever. J Pediatr. 2015;166(5):1246-1251. doi: 10.1016/j. jpeds.2015.02.015

104. Poyhonen H, Nurmi M, Peltola V, Alaluusua S, Ruuskanen O, Lahdesmaki T. Dental staining after doxycycline use in children. J Antimicrob Chemother. 2017;72(10):2887-2890. doi: 10.1093/jac/dkx245

105. Baxter BT, Pearce WH, Waltke EA, et al. Prolonged administration of doxycycline in patients with small asymptomatic abdominal aortic aneurysms: report of a prospective (Phase II) multicenter study. J Vasc Surg. 2002;36(1):1-12. doi: 10.1067/mva.2002.125018

106. Arthur JD, Echeverria P, Shanks GD, Karwacki J, Bodhidatta L, Brown JE. A comparative study of gastrointestinal infections in United States soldiers receiving doxycycline or mefloquine for malaria prophylaxis. Am J Trop Med Hyg. 1990;43(6):608-613. doi: 10.4269/ajtmh.1990.43.608

107. Ayaslioglu E, Erkek E, Oba AA, Cebecioglu E. Doxycycline-induced staining of permanent adult dentition. Aust Dent J. 2005;50(4):273-275. doi: 10.1111/j.1834-7819.2005.tb00373.x

108. Good ML, Hussey DL. Minocycline: stain devil? $\mathrm{Br} \mathrm{J}$ Dermatol. 2003;149(2):237-239. doi: 10.1046/j.13652133.2003.05497.x

109. Gordon PH, Moore DH, Miller RG, et al. Efficacy of minocycline in patients with amyotrophic lateral sclerosis: a phase III randomised trial. Lancet Neurol. 2007;6(12):1045-1053. doi: 10.1016/S14744422(07)70270-3

110. Carris NW, Pardo J, Montero J, Shaeer KM. Minocycline as a substitute for doxycycline in targeted scenarios: a systematic review. Open Forum Infectious Diseases. 2015;2(4). doi: 10.1093/ofid/ofv178

111. Chen YC, Hsu WY, Chang TH. Macrolide-resistant Mycoplasma pneumoniae infections in pediatric community-acquired pneumonia. Emerg Infect Dis. 2020;26(7):1382-1391. doi:10.3201/eid2607.200017

112. Cao B, Zhao C-J, Yin Y-D, et al. High prevalence of macrolide resistance in Mycoplasma pneumoniae isolates from adult and adolescent patients with respiratory tract infection in China. Clin Infect Dis. 2010;51(2):189-194. doi: 10.1086/653535

113. Yin YD, Wang R, Zhuo C, et al. Macrolide-resistant Mycoplasma pneumoniae prevalence and clinical aspects in adult patients with community-acquired pneumonia in China: A prospective multicenter surveillance study. J Thorac Dis. 2017;9(10):3774-3781. doi:10.21037/jtd.2017.09.75

114. Zhou Z, Li X, Chen X, et al. Macrolide-resistant Mycoplasma pneumoniae in adults in Zhejiang, China. Antimicrob Agents Chemother. 2015;59(2):1048-1051. doi: 10.1128/AAC.04308-14

115. Cao B, Qu J, Yin Y, Eldere J Van. Overview of antimicrobial options for Mycoplasma pneumoniae pneumonia: focus on macrolide resistance. Clin Respir J. 2017;11(4):419-429. doi: 10.1111/crj.12379

116. Morozumi M, Hasegawa K, Kobayashi R, et al. 
Emergence of macrolide-resistant Mycoplasma pneumoniae with a $23 \mathrm{~S}$ rRNA gene mutation. Antimicrob Agents Chemother. 2005;49(6):2302-2306. doi: 10.1128/AAC.49.6.2302-2306.2005

117. Suzuki S, Yamazaki T, Narita M, et al. Clinical evaluation of macrolide-resistant Mycoplasma pneumoniae. Antimicrob Agents Chemother. 2006;50(2):709-712. doi: 10.1128/AAC.50.2.709-712.2006

118. Tanaka T, Oishi T, Miyata I, et al. Macrolide-resistant Mycoplasma pneumoniae infection, Japan, 20082015. Emerg Infect Dis. 2017;23(10):1703-1706. doi: 10.3201/eid2310.170106

119. Degrange S, Renaudin $\mathrm{H}$, Charron A, Pereyre S, Bebear C, Bebear CM. Reduced susceptibility to tetracyclines is associated in vitro with the presence of $16 \mathrm{~S}$ rRNA mutations in Mycoplasma hominis and Mycoplasma pneumoniae. I Antimicrob Chemother. 2008;61(6):1390-1392. doi: 10.1093/jac/dkn118

120. Liverani E, Banerjee S, Roberts W, Naseem KM, Perretti M. Prednisolone exerts exquisite inhibitory properties on platelet functions. Biochem Pharmacol. 2012;83(10):1364-1373. doi: 10.1016/j. bcp.2012.02.006 